\title{
UNIT PENANGKAPAN JARING ARAD
}

\author{
Agus Salim ${ }^{1)}$ dan Suwardi') \\ Teknisi Litkayasa pada Balai Riset Perikanan Laut, Muara Baru-Jakarta
}

Teregristasi I tanggal: 21 Maret 2006; Diterima setelah perbaikan tanggal: 26 Januari 2007; Disetujui terbit tanggal: 9 Mei 2007

\section{PENDAHULUAN}

Jaring arad merupakan hasil modifikasi dari jaring trawl yang telah diatur penggunaannya melalui Keputusan Presiden No.39 tahun 1980. Pada tahun 1990-an jaring arad berkembang pesat dan tersebar luas terutama di pantai utara Jawa. Penamaan terhadap alat tangkap ini bermacam-macam seperti trwalmini, pukat kucing, dogol, dan lain-lain.

Dalam pengoperasian jaring arad memerlukan beberapa alat bantu operasional yaitu papan sewakan sebagai alat pembuka jaring, tali layang-layang yang ada disewakan berguna sebagai pengatur bekerja sewakan, dan tali slambar yang menghubungkan antara tali cabang dengan kapal sebagai penarik jaring.

Jaring arad tergolong alat tangkap pukat dasar, karena alat ini terbagi atas sayap, badan, dan kantong. Dan pengoperasian adalah dengan cara ditarik menggunakan tenaga kapal sampai dengan menyapu dasar perairan yang lunak dan rata.

Hasil tangkapan jaring arad pada umumnya terdiri atas jenis-jenis ikan dasar seperti beloso, gulamah, petek, kurisi, kuniran, dan lain-lain. Dan dari jenisjenis non ikan yang tertangkap seperti udang, cumicumi, kepiting, kerang, dan simping.

\section{BAHAN DAN METODE}

Data dan informasi dalam tulisan ini merupakan hasil pengamatan yang dilakukan di Jambean, Wonokerto Wetan, Pekalongan pada bulan Nopember sampai dengan Desember 2004. Pengamatan dilakukan dengan cara mengikuti operasi penangkapan jaring arad dan wawancara dengan nelayan. Pengumpulan data dan informasi operasi jaring arad dilakukan 5 trip.

\section{Kapal}

Kapal yang digunakan pada umumnya terbuat dari bahan kayu jati dengan ukuran tebal papan 2 sampai dengan $3 \mathrm{~cm}$. Kapal berbentuk Sopek dengan panjang (LOA) 7 sampai dengan $8,5 \mathrm{~m}$, lebar (B) 1,5 sampai dengan 2,8 $\mathrm{m}$ dan dalam (D) 0,8 sampai dengan 1,2 m. Kapal untuk mengoperasikan jaring arad dirancang dan dibuat oleh pekerja setempat turun-temurun dengan cara yang sederhana.

\section{Tenaga Penggerak}

Tenaga penggerak yang umum digunakan oleh nelayan jaring arad adalah mesin diesel out board dengan menggunakan as panjang. Rata-rata kapal menggunakan 2 mesin (double engine) untuk menjalankan kapal dan menarik jaring. Mesin yang digunakan kebanyakan merk Dongfeng dengan kekuatan berkisar antara 11 sampai dengan 20 PK.

\section{Deskripsi Alat Tangkap}

Jaring arad pada umumnya menggunakan bahan utama badan jaring (webbing) poly ethylin. Material ini di samping kuat, ringan, dan tahan lama. Jaring arad terbagi atas 3 bagian utama yaitu kantong (cod end), badan (body), dan sayap (wing).

Kantong terbuat dari bahan poly ethylin D6 dan D9 dengan ukuran mata mata jaring mata jaring (mesh size) 0,5 sampai dengan 1 inci. Panjang kantong 2 sampai dengan $3 \mathrm{~m}$ dengan jumlah mata melingkar 125 sampai dengan 150 mata jaring.

Badan terbuat dari bahan poly ethylin D6 dengan ukuran mata jaring (mesh size) 1 sampai dengan 2 inci. Panjang bagian badan 6 sampai dengan $13 \mathrm{~m}$ dengan jumlah mata melingkar 300 sampai dengan 450 mata jaring.

Sayap terbuat dari bahan poly ethylin D6 dengan ukuran mata jaring (mesh size) 2 sampai dengan 4 inci. Panjang sayap 12 sampai dengan $24 \mathrm{~m}$ dengan jumlah mata melingkar bagian dalam 150 sampai dengan 200 dan bagian ujung 60 sampai dengan 100 mata jaring (Gambar 1).

\section{HASIL DAN BAHASAN}

\section{Perlengkapan Operasional}

Jaring arad dalam pengoperasian dilengkapi dengan papan pembuka sewakan (otter board), tali layang-layang, tali cabang (bridle), dan tali selambar (warp). Untuk mendapatkan hasil yang maksimal perlengkapan berikut mutlak diperlukan agar 
memperoleh bukaan atau tampilan untuk yang baik yaitu:

\section{Papan Pembuka atau Sewakan (Otter Board)}

Berfungsi sebagai pembuka mulut jaring yang dipasang pada ke-2 ujung sayap jaring sehingga ketika jaring ditarik ke-2 papan saling menjauh dan membentang dengan baik. Papan ini terbuat dari kayu jati dengan ukuran tebal 1,5 sampai dengan $2 \mathrm{~cm}$, panjang 60 sampai dengan $80 \mathrm{~cm}$ dan lebar 30 sampai dengan $40 \mathrm{~cm}$. Bagian bawah papan dipasang pipa besi dengan diameter 2,5 sampai dengan 3 inci sepanjang $50 \mathrm{~cm}$ yang diisi dengan semen cor sebagai pemberat. Total bobot sepasang papan pembuka 30 sampai dengan $40 \mathrm{~kg}$.

\section{Tali Layang-Layang}

Tali layang layang terbuat dari bahan poly ethylene, berdiameter 10 sampai dengan $12 \mathrm{~mm}$ berjumlah 4 utas tali, 1 ujung diikat menempel pada papan pembuka, sedang ujung sebelah yang lain dikumpulkan dan diikat menjadi 1 untuk ke tali selambar.

\section{Tali Cabang (Bridle)}

Tali cabang adalah tali yang menghubungkan antara papan pembuka dengan tali selambar. Bagian tali ini terbuat dari bahan poly ethylin dengan diameter 12 sampai dengan $16 \mathrm{~mm}$, dan panjang 35 sampai dengan $40 \mathrm{~m}$. Kedua ujung tali cabang diikatkan pada papan pembuka sedangkan ujung yang lain dihubungkan dengan tali selambar.

\section{Tali Selambar (Warp)}

Tali selambar adalah tali yang menghubungkan antara tali cabang dengan kapal sebagai penarik jaring saat pengoperasian alat tangkap (towing). Tali cabang terbuat dari bahan poly ethylin dengan diameter 16 sampai dengan $20 \mathrm{~mm}$ dan panjang 200 sampai dengan $300 \mathrm{~m}$.

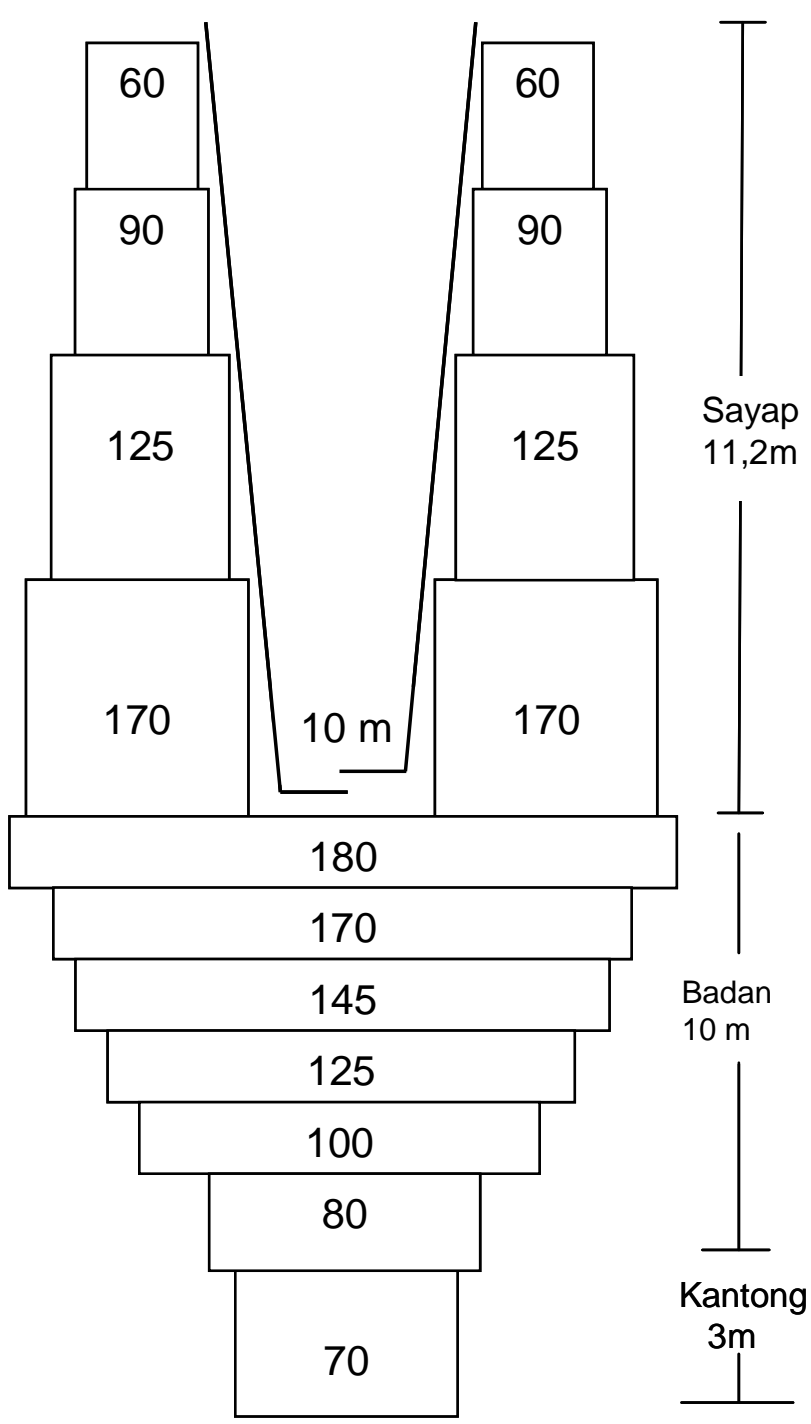

Gambar 1. Desain jaring arad yang dioperasikan di Jambean, Wonokerto Wetan, Pekalongan. 


\section{Cara Pengoperasian}

Jaring arad tergolong alat tangkap aktif yang dioperasikan di dasar perairan. Pengoperasian dilakukan dengan cara ditarik dengan menggunakan kapal. Tahapan penurunan jaring sebagai berikurt (Gambar 2).

1. Ujung tali selambar diikat pada kapal dan ujung yang lain diikatkan pada tali cabang, dan ke-2 ujung tali cabang dihubungkan dengan tali layanglayang pada papan pembuka. Papan pembuka disambung dengan ujung sayap jaring dan tali kantong diikat (dimatikan).

2. Pada saat tawur jaring arad kapal dalam keadaan bergerak maju, bagian yang pertama yang diturunkan adalah bagian kantong kemudian badan, sayap, dan tali cabang. Setelah sampai dengan tali cabang penurunan dihentikan sementara atau ditahan untuk mengetahui papan pembuka bekerja dengan baik. Setelah papan pembuka bekerja dengan baik kemudian tali selambar diturunkan 5 sampai dengan 7 kali kedalaman perairan dengan kecepatan kapal bergerak antara 5 sampai dengan 6 knot.

3. Penarikan jaring (towing) dilakukan antara 1 sampai dengan 3 jam, kecepatan kapal 2 sampai dengan 3 knot.

4. Penarikan jaring setelah towing dilakukan dengan menggunakan bantuan mesin gardan sampai dengan papan pembuka naik ke atas kapal. Setelah papan pembuka naik ke atas kapal jaring diangkat dengan menggunakan tenaga manusia.

\section{Hasil Tangkapan}

Selama melakukan pengamatan dilapangan (5 trip) diperoleh rata-rata hasil tangkapan $20,71 \mathrm{~kg}$ per tawur jaring atau 49,70 $\mathrm{kg}$ per trip. Dalam 1 trip dapat dilakukan 2 sampai dengan 3 kali pengangkatan. Hasil tangkapan secara umum didominasi oleh jenis-jenis ikan demersal seperti ikan bloso, petek, kurisi, kuniran, dan buntal. Bagian kecil hasil tangkapan berupa udang, cumi-cumi, sotong, kepiting, dan simping yang merupakan tangkapan andalan dikarenakan harga yang relatif tinggi dibandingkan dengan hasil tangkapan lain.

Tabel $1 . \quad$ Hasil tangkapan arad

\begin{tabular}{|c|c|c|c|c|c|c|c|}
\hline \multirow[t]{2}{*}{ No. } & \multirow[t]{2}{*}{ Nama ikan } & \multirow{2}{*}{$\begin{array}{l}27-11-04 \\
\text { (3 tawur) } \\
\text { Bobot (g) } \\
\end{array}$} & \multirow{2}{*}{$\begin{array}{l}28-11-04 \\
\text { (2 tawur) } \\
\text { Bobot }(g) \\
\end{array}$} & \multirow{2}{*}{$\begin{array}{l}29-11-04 \\
\text { (3 tawur) } \\
\text { Bobot (g) }\end{array}$} & \multirow{2}{*}{$\begin{array}{l}30-11-04 \\
\text { (2 tawur) } \\
\text { Bobot }(\mathrm{g}) \\
\end{array}$} & \multirow{2}{*}{$\begin{array}{l}01-12-05 \\
\text { (2 tawur) } \\
\text { Bobot }(\mathrm{g}) \\
\end{array}$} & \multirow{2}{*}{$\frac{\text { Total }}{\text { Bobot (g) }}$} \\
\hline & & & & & & & \\
\hline 1. & Bloso & 27.450 & 1.130 & 4.840 & 4.500 & 7.100 & 45.020 \\
\hline 2. & Petek & 4.120 & 4.200 & 800 & 34.200 & 7.300 & 50.620 \\
\hline 3. & Kurisi & 6.700 & 10.400 & 900 & 15.200 & 16.500 & 49.700 \\
\hline 4. & Kuniran & 2.350 & 2.050 & 530 & 3.300 & 4.500 & 12.730 \\
\hline 5. & Gulamah & 2.400 & 950 & 90 & 1.800 & 1.050 & 6.290 \\
\hline 6. & Buntal & 4.200 & 4.000 & 380 & 3.800 & 1.850 & 14.230 \\
\hline 7. & Sriding & 2.600 & 3.200 & 1.400 & 650 & 1.200 & 9.050 \\
\hline 8. & Lidah & 300 & 150 & 80 & 300 & 160 & 990 \\
\hline 9. & Sebelah & 240 & 480 & 480 & 1.150 & 520 & 2.870 \\
\hline 10. & Kapasan & 570 & 300 & 370 & 1.600 & 30 & 2.870 \\
\hline 11. & Semadar & 450 & - & 150 & 250 & 150 & 1.000 \\
\hline 12. & Kuwe & 550 & 140 & 20 & - & 300 & 1.010 \\
\hline 13. & Swanggi & 750 & 1.600 & 570 & 200 & 350 & 3.470 \\
\hline 14. & Remang & 400 & - & - & 2.000 & - & 2.400 \\
\hline 15. & Gerot-gerot & 870 & 100 & - & - & 150 & 1.120 \\
\hline 16. & Utik & - & 400 & - & - & - & 400 \\
\hline 17. & Alu-alu & - & 50 & 50 & 500 & 200 & 800 \\
\hline 18. & Stop-stop & 20 & 230 & 20 & 150 & - & 420 \\
\hline 19. & Kakap & - & - & 40 & - & - & 40 \\
\hline 20. & Kerapu & - & - & 580 & - & - & 580 \\
\hline 21. & Kembung & - & - & - & 150 & - & 150 \\
\hline 22. & Udang & 1.730 & 720 & 610 & 1.850 & 1.020 & 5.930 \\
\hline 23. & Cumi & 4.600 & 1.250 & 550 & 3.500 & 1.300 & 11.200 \\
\hline 24. & Sotong & 6.100 & 1.200 & 1.650 & 2.800 & 1.700 & 13.450 \\
\hline 25. & Gurita & 800 & - & 300 & 1.000 & 250 & 2.350 \\
\hline 26. & Simping & 1.000 & 2.200 & 1.000 & 500 & 800 & 5.500 \\
\hline 27. & Kepiting & 370 & 350 & 650 & 250 & 450 & 2.070 \\
\hline \multirow[t]{2}{*}{28.} & Lain-lain & 130 & 50 & 440 & 800 & 800 & 2.020 \\
\hline & Total & 68.700 & 35.150 & 16.500 & 80.450 & 47.680 & 248.480 \\
\hline
\end{tabular}




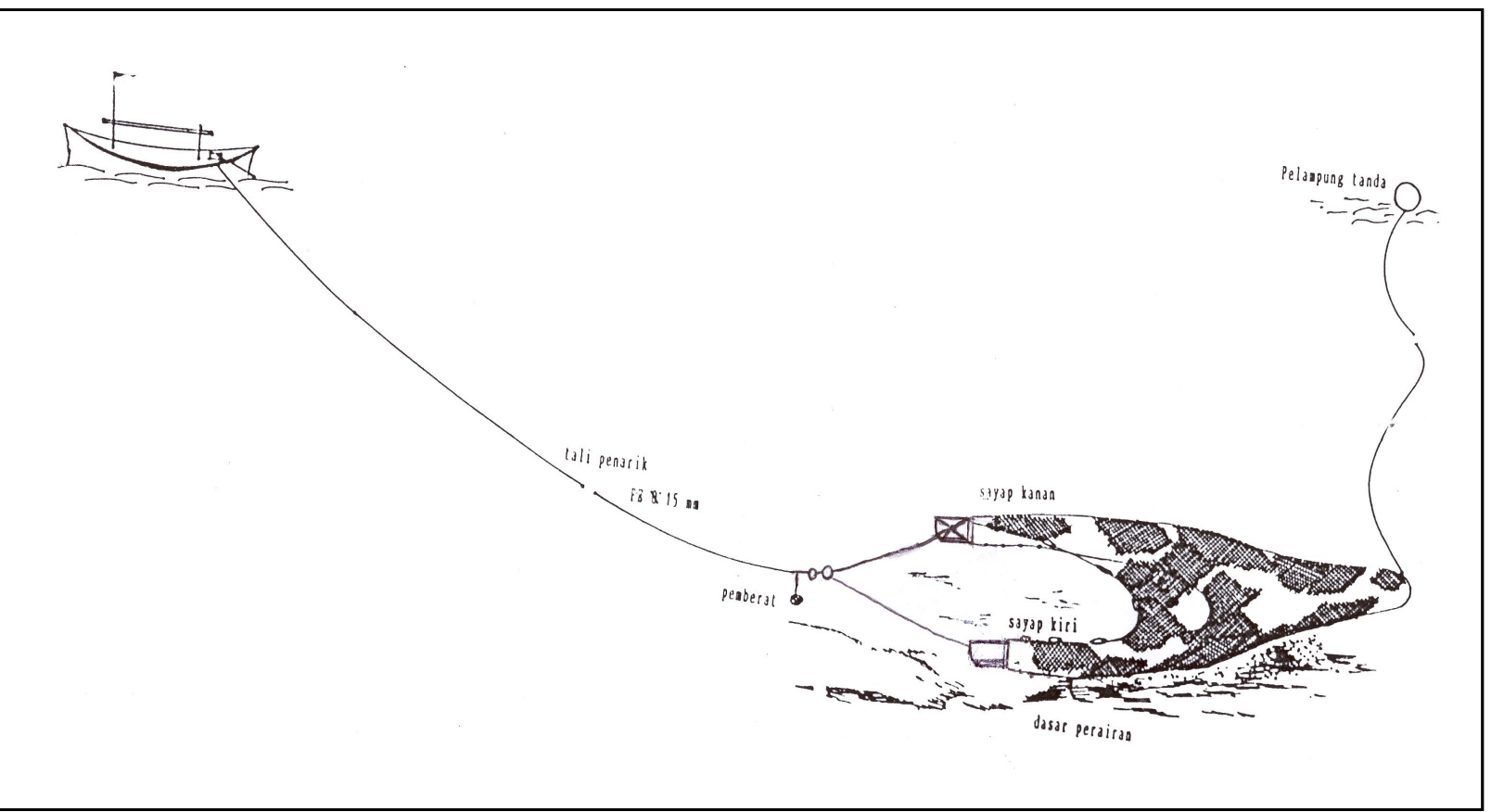

Gambar 2. Pengoperasian jaring arad.

\section{KESIMPULAN DAN SARAN}

1. Jaring arad merupakan jaring pukat karena mempunyai bagian kantong, badan dan, sayap. Dalam pengoperasian jaring arad menggunakan papan sewakan untuk membuka mulut jarring.

2. Dalam pengoperasian jaring arad merupakan alat tangkap aktif yang dioperasikan dengan cara ditarik di dasar perairan.
3. Hasil tangkapan rata-rata $20,71 \mathrm{~kg}$ per tawur atau 49,70 kg per trip.

4. Hasil tangkapan didominasi oleh jenis ikan-ikan demersal seperti beloso, petek, kurisi, dan buntal.

5. Dilihat dari segi ekonomi alat tangkap jaring arad cukup menguntungkan bagi para nelayan kecil.

6. Perlu dipertimbangkan penggunaan ukuran mata jaring dan penggunaan dan perangkat selektif yang menunjang kelestarian sumber daya. 